\title{
Biogeochemical variability in the central equatorial Indian Ocean during the monsoon transition
}

\author{
P. G. Strutton ${ }^{1}$, V. J. Coles ${ }^{2}$, R. R. Hood ${ }^{2}$, R. J. Matear ${ }^{3}$, M. J. McPhaden ${ }^{4}$, and H. E. Phillips ${ }^{1}$ \\ ${ }^{1}$ Institute for Marine and Antarctic Studies, University of Tasmania, and Australian Research Council Centre of Excellence \\ for Climate System Science, Hobart, Australia \\ ${ }^{2}$ Horn Point Laboratory, University of Maryland Center for Environmental Sciences, Cambridge, USA \\ ${ }^{3}$ Commonwealth Scientific and Industrial Research Organisation, Marine and Atmospheric Research, Hobart, Australia \\ ${ }^{4}$ National Oceanic and Atmospheric Administration, Pacific Marine Environmental Laboratory, Seattle, WA, USA \\ Correspondence to: P. G. Strutton (peter.strutton@utas.edu.au)
}

Received: 15 January 2014 - Published in Biogeosciences Discuss.: 29 April 2014

Revised: 18 February 2015 - Accepted: 27 February 2015 - Published: 23 April 2015

\begin{abstract}
In this paper we examine time-series measurements of near-surface chlorophyll concentration from a mooring that was deployed at $80.5^{\circ} \mathrm{E}$ on the equator in the Indian Ocean in 2010. These data reveal at least six striking spikes in chlorophyll from October through December, at approximately 2 -week intervals, that coincide with the development of the fall Wyrtki jets during the transition between the summer and winter monsoons. Concurrent meteorological and in situ physical measurements from the mooring reveal that the chlorophyll pulses are associated with the intensification of eastward winds at the surface and eastward currents in the mixed layer. These observations are inconsistent with upwelling dynamics as they occur in the Atlantic and Pacific oceans, since eastward winds that force Wyrtki jet intensification should drive downwelling. The chlorophyll spikes could be explained by two alternative mechanisms: (1) turbulent entrainment of nutrients and/or chlorophyll from across the base of the mixed layer by wind stirring or Wyrtki jet-induced shear instability or (2) enhanced southward advection of high chlorophyll concentrations into the equatorial zone. The first mechanism is supported by the phasing and amplitude of the relationship between wind stress and chlorophyll, which suggests that the chlorophyll spikes are the result of turbulent entrainment driven by synoptic zonal wind events. The second mechanism is supported by the observation of eastward flows over the Chagos-Laccadive Ridge, generating high chlorophyll to the north of the equator. Occasional southward advection can then produce the chlorophyll spikes that are observed in the mooring record.
\end{abstract}

Wind-forced biweekly mixed Rossby gravity waves are a ubiquitous feature of the ocean circulation in this region, and we examine the possibility that they may play a role in chlorophyll variability. Statistical analyses and results from the OFAM3 (Ocean Forecasting Australia Model, version 3) eddy-resolving model provide support for both mechanisms. However, the model does not reproduce the observed spikes in chlorophyll. Climatological satellite chlorophyll data show that the elevated chlorophyll concentrations in this region are consistently observed year after year and so are reflective of recurring large-scale wind- and circulationinduced productivity enhancement in the central equatorial Indian Ocean.

\section{Introduction}

Although our ability to describe and model the oceans has advanced rapidly in recent decades, our understanding of the biogeochemical and ecological dynamics of the Indian Ocean is still rudimentary in many respects. This is due, in part, to the fact that the Indian Ocean remains undersampled in both time and space compared to the Pacific and Atlantic. Moreover, the Indian Ocean is a dynamically complex and highly variable system under monsoonal influence. Although recent focused research in the Indian Ocean has significantly improved our ability to understand and predict physical dynamics and ocean-atmosphere interactions (Schott et al., 2009), the biogeochemical and ecological im- 

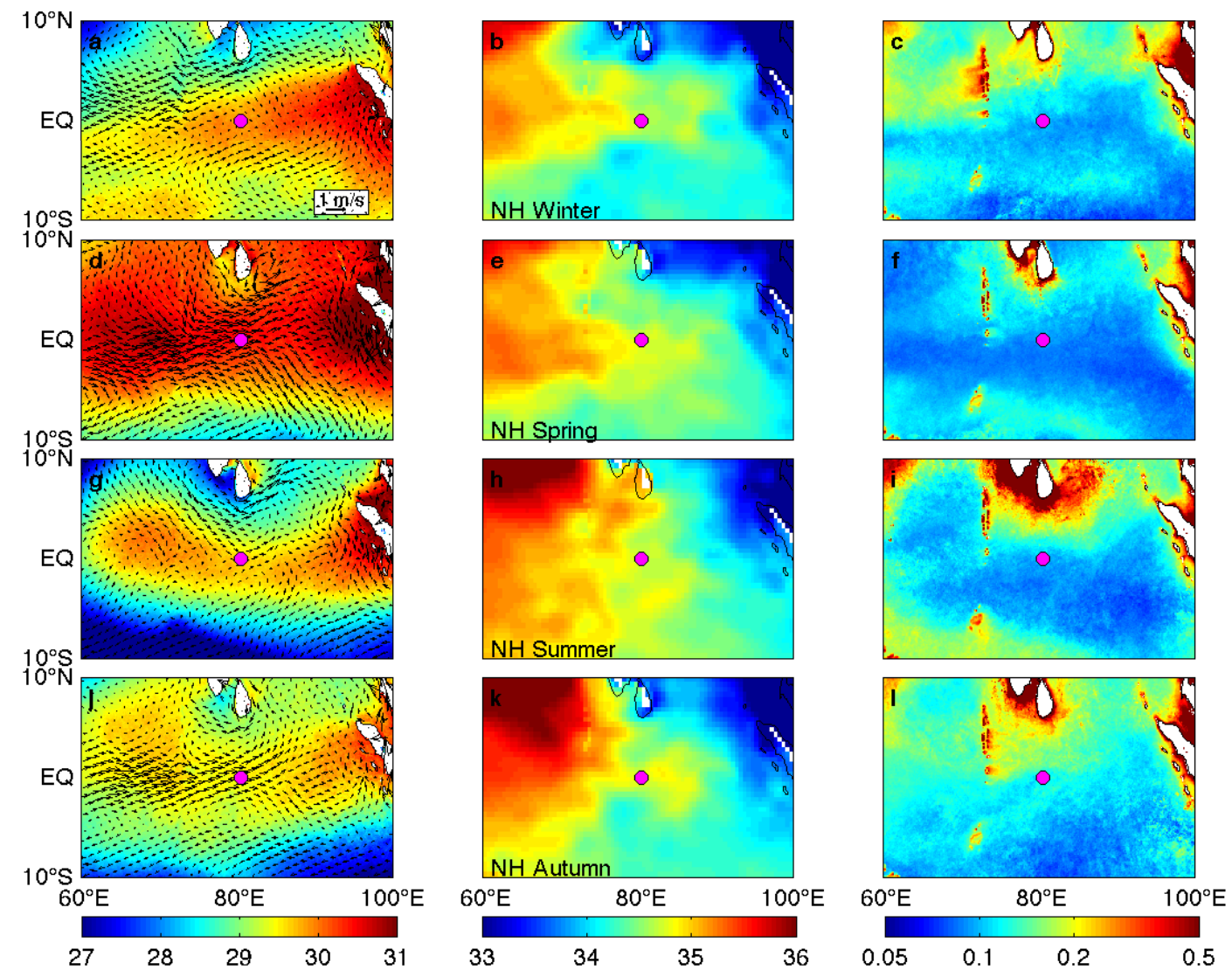

Figure 1. The seasonal climatology of SST (sea surface temperature) and OSCAR (Ocean Surface Current Analysis Real-time) currents (left column of panels), salinity (center column) and chlorophyll (right column) for a region of the Indian Ocean encompassing the RAMA (Research Moored Array for African-Asian-Australian Monsoon Analysis and Prediction) mooring at the equator, $80.5^{\circ}$ E. SST and chlorophyll data sets are from the MODIS (MODerate resolution Imaging Spectroradiometer) Aqua satellite at $9 \mathrm{~km}$ spatial resolution. Salinity data are from the CSIRO Atlas of Regional Seas (CARS: http://www.marine.csiro.au/). The seasons are defined as follows: boreal winter 21 December to 21 March; spring - 21 March to 20 June; summer - 21 June to 21 September; autumn - 21 September to 21 December. The seasonal climatology illustrates the potential for salty, high-chlorophyll waters to be advected into the vicinity of the mooring in boreal autumn.

pacts of this complex physical forcing are not yet fully understood (Hood et al., 2009). This is particularly true in the equatorial zone, where atmospheric forcing and the physical response have been relatively well studied but the biogeochemical and ecological responses have not.

Much of what is known about biogeochemical variability in the equatorial zone of the Indian Ocean is derived from satellite ocean color observations and models, combined with relatively sparse in situ measurements. SeaWiFS (Sea-viewing Wide Field-of-view Sensor) monthly and seasonal climatologies of near-surface chlorophyll concentration reveal a strong seasonality in productivity in equatorial waters that is clearly linked to monsoon forcing (Fig. 1, Wiggert et al., 2006). In general, chlorophyll concentrations increase from the equator northward with lowest basin-wide concentrations $\left(<0.1 \mathrm{mg} \mathrm{m}^{-3}\right)$ observed during the spring intermonsoon time period (March-May, Fig. 1f). During the southwest monsoon (July-September,
Fig. 1i), concentrations increase dramatically in the northern Indian Ocean and in western equatorial waters in response to monsoon-forced upwelling and mixing, but concentrations in the central equatorial waters around $80^{\circ} \mathrm{E}$ remain relatively low $\left(<0.5 \mathrm{mg} \mathrm{m}^{-3}\right)$, just south of high concentrations off of southern India and Sri Lanka. Dramatic island wake effects can be seen sweeping high-chlorophyll water $\left(>0.5 \mathrm{mg} \mathrm{m}^{-3}\right)$ eastward along the equator from the Chagos-Laccadive Ridge at $73^{\circ} \mathrm{E}$ (Fig. 1i), reversing and sweeping westward in February-March (Fig. 1c).

In situ observations reveal a well-developed deep chlorophyll maximum in the western equatorial Indian Ocean along $65^{\circ} \mathrm{E}$ between $8^{\circ} \mathrm{S}$ and $8^{\circ} \mathrm{N}$ centered at about $50 \mathrm{~m}$ in November-December (George et al., 2013). Whether or not this subsurface maximum persists throughout the year along the equator is unclear, but it is very likely also present during the spring intermonsoon period (March-May) when the water column is stratified. Both satellite observations and 
models predict the presence of a deep chlorophyll maximum centered at $60 \mathrm{~m}$ depth south of the equator between 55 and $75^{\circ} \mathrm{E}$ in the vicinity of the Seychelles-Chagos thermocline ridge (SCTR $\sim 5$ to $10^{\circ} \mathrm{S}$ ) throughout the year, except during periods of strong wind-induced mixing and entrainment (Resplandy et al., 2009). Similarly, models predict the presence of a deep $(60 \mathrm{~m})$ chlorophyll maximum in eastern Indian Ocean equatorial waters $\left(87^{\circ} \mathrm{E}\right.$; Wiggert et al., 2006). This deep maximum is present throughout the year except during the southwest monsoon when high-chlorophyll surface water is advected into the region.

The equatorial Indian Ocean is strongly influenced by physical processes on intraseasonal to interannual timescales. Here we briefly describe the major modes of variability. Wyrtki jets occur semiannually during intermonsoon periods (Han et al., 1999; Wyrtki, 1973), and some of their physical properties are described below. The MaddenJulian oscillation (MJO) is characterized by atmospheric variability, with periods of 30-60 days and eastward propagation of atmospheric convection cells (Madden and Julian, 1971; Hendon and Salby, 1994). Wind, surface heat flux, and rainfall anomalies associated with the MJO stimulate dynamical and thermodynamical responses in the upper Indian Ocean (McPhaden and Foltz, 2013). The Indian Ocean Dipole (IOD) is a basin-wide phenomenon that can be classified into positive and negative events. Positive events exhibit unusually strong easterly equatorial winds and anomalous upwelling, meaning cooler SSTs (sea surface temperatures), in the eastern Indian Ocean (Saji et al., 1999; Vinayachandran et al., 2009). Roughly 16 positive and 9 negative events occurred over the period 1950-2004 (Ihara et al., 2008). The time period of our measurements in 2010 encompassed a negative IOD event (Horii et al., 2013).

All of these physical processes have been shown to influence biogeochemistry. For example, satellite observations have shown that IOD events significantly increase chlorophyll concentrations and primary production in eastern Indian Ocean equatorial waters, and they can also influence chlorophyll and production over the entire northern basin (Wiggert et al., 2009). In situ data from the central equatorial Indian Ocean have been used to show how the relaxation of an IOD event influences physical structure and how this can deplete upper-ocean nutrients, decreasing biologically productivity (Kumar et al., 2012). It has also been demonstrated that these biogeochemical responses to the IOD have significant higher trophic level impacts (Marsac and Le Blanc, 1999).

The analysis of satellite chlorophyll concentrations suggests that MJO wind-induced mixing drives a response of surface chlorophyll on large scales, especially in the North Indian Ocean (Waliser et al., 2005). Using satellite observations and biophysical model simulations, Resplandy et al. (2009) showed how chlorophyll concentrations and primary production in the vicinity of the Seychelles-Chagos thermocline ridge can be increased by MJO-induced wind mixing and nutrient fertilization. They also concluded that the biogeochemical response to MJO is highly dependent on IOD-driven interannual variability of thermocline depth. Specifically, following Indian Ocean Dipole events, the deepened nutricline prevents nutrient input into the mixed layer, decreasing the biogeochemical response to MJO.

The Wyrtki jets, which are narrow currents flowing eastward along the equator at peak speeds of about $1 \mathrm{~m} \mathrm{~s}^{-1}$ (Nagura and McPhaden, 2010a; Joseph et al., 2012), occur with regularity every boreal spring and fall (Fig. 1d, $\mathrm{j}$ ), though there is significant interannual variability in their strength associated with the IOD (Schott and McCreary, 2001; Nagura and McPhaden, 2010b). The spring jet is strongest in April-May (Fig. 1d) and the fall jet is strongest from late October to early December (Fig. 1j); its formation is accompanied by thermocline uplift in the western basin and by thermocline depression in the east (Wyrtki, 1973).

Wiggert et al. (2006) argued that the main biogeochemical impact of the Wyrtki jets is to depress the thermocline and nitracline on the eastern side of the basin and therefore lower equatorial primary production upon their arrival in May and November. This pattern was observed in a 25-day shipboard time series from the equator at $80.5^{\circ} \mathrm{E}$ in late 2006 that revealed deepening of the surface layer, nitracline and subsurface chlorophyll maximum during the fall Wyrtki jet period (Kumar et al., 2012). However, these data also revealed a biweekly shoaling of the lower thermocline and the depth of the chlorophyll maximum associated with the passage of mixed Rossby-gravity (MRG) waves. These waves, first observed in the atmosphere by Yanai and Maruyama (1966), are equatorially trapped planetary waves with a Gaussian structure in meridional velocity that is centered at the equator. In the atmosphere they strongly influence both the Indian monsoon during the northern summer and the Australian monsoon during the northern winter (Chatterjee and Goswami, 2004). MRG waves are generated in the ocean by fluctuations in meridional wind stress, and they can propagate eastward or westward depending on their period. There have been several studies documenting the physical impacts of these waves in the Indian Ocean. Among other things, it has been shown that MRG waves are strongly coherent with the local meridional wind stress (Ogata et al., 2008) and, when propagating westward, that they can drive fluctuating upwelling and downwelling circulations with an amplitude of 2-3 day $^{-1}$ (Sengupta et al., 2004). When the phase is propagating eastward, they behave like inertia-gravity waves, and they can be seen in time-series data as upward phase propagation in the meridional velocities at approximately 2-week intervals (Kumar et al., 2012). During positive phases of the IOD, David et al. (2011) observed Yanai waves with significantly longer periods of 24 to 40 days. Although Sengupta et al. (2004) speculate that MRG waves might have implications for the biogeochemistry of the Indian Ocean, besides Kumar et al. (2012), there have been no studies revealing a significant biogeochemical impact from their passage. 
Table 1. The following observations are available from the mooring location (McPhaden et al., 2009). Some of these data were not available for the entire deployment due to sensor failure. Acoustic Doppler current profiler (ADCP) data are measured at $8 \mathrm{~m}$ vertical resolution.

\begin{tabular}{ll}
\hline Observation & Height relative to sea surface \\
\hline Shortwave solar radiation & $3.5 \mathrm{~m}$ \\
Longwave solar radiation & $3.5 \mathrm{~m}$ \\
Rain rate & $3.5 \mathrm{~m}$ \\
Wind speed and direction & $4 \mathrm{~m}$ \\
Relative humidity & $3 \mathrm{~m}$ \\
Barometric pressure & $3 \mathrm{~m}$ \\
Air temperature & $3 \mathrm{~m}$ \\
Ocean temperature & $-1,-5,-10,-13,-20$, \\
& $-40,-43,-60,-80,-100$, \\
& $-120,-140,-180,-300,-500 \mathrm{~m}$ \\
Salinity & $-1,-10,-20,-40$, \\
& $-60,-100,-140 \mathrm{~m}$ \\
Current speed and direction & $-10,-40 \mathrm{~m}$ \\
Depth of the $20^{\circ} \mathrm{C}$ isotherm & \\
ADCP-derived currents & -30 to $\geq 200 \mathrm{~m}$ \\
\hline
\end{tabular}

To better characterize these and other kinds of atmospheric and oceanic variability in the Indian Ocean, CLIVAR (the climate variability and predictability program) and GOOS (the Global Ocean Observing System) have supported deployment of a basin-wide observing system in the Indian Ocean, called the Indian Ocean Observing System, or IndOOS (International CLIVAR Project Office, 2006). A central component of IndOOS is the Research Moored Array for African-Asian-Australian Monsoon Analysis and Prediction, or RAMA (McPhaden et al., 2009), which consists of 46 moored buoys spanning the entire basin between $16^{\circ} \mathrm{N}$ and $26^{\circ} \mathrm{S}$. RAMA, currently under development, is $74 \%$ complete as of March 2015. These moorings are capable of measuring a broad suite of key variables needed to describe, understand and predict large-scale ocean dynamics and ocean-atmosphere interactions (Table 1). They also provide an excellent atmospheric and physical oceanographic context for biogeochemical studies in the Indian Ocean.

In this paper we describe results from the first biogeochemical sensor deployment on a RAMA mooring, along with concurrent atmospheric, physical oceanographic and remote-sensing measurements. These data reveal a series of striking chlorophyll spikes at approximately 2-week intervals in October through December that are more than 2.5 times the magnitude of chlorophyll peaks in spring and summer of 2010 (Fig. 2). These events occurred during the development of the fall Wyrtki jet. The timing of the spikes appears to be related to local synoptic wind events and local entrainment at the equator, but satellite chlorophyll observations also reveal that these spikes occur during a period of high chlorophyll just north of the equator, emanating from the Chagos-Laccadive Ridge upstream. The 2-week intervals between chlorophyll spikes suggest a possible link to MRG waves. Using observations, combined with insights obtained

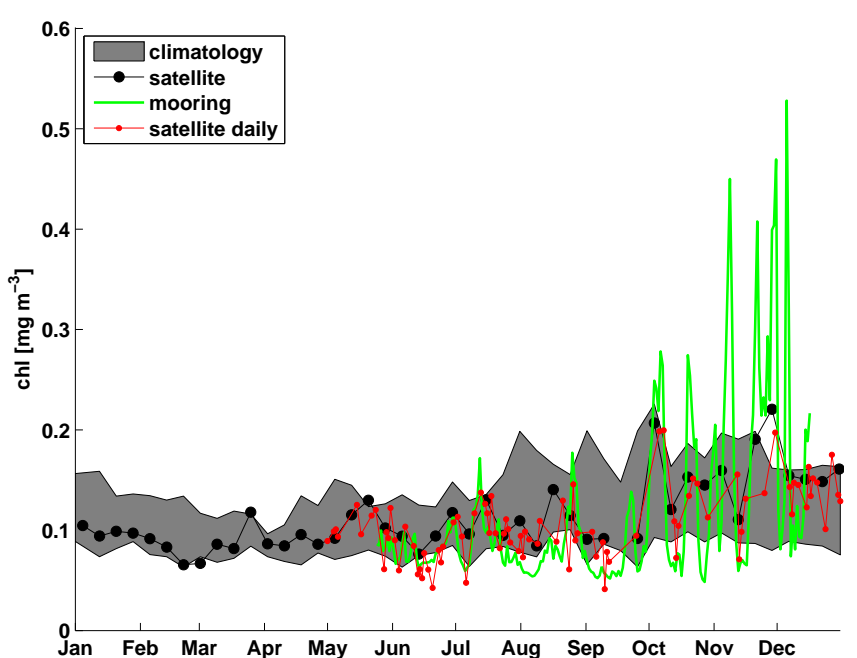

Figure 2. Chlorophyll concentrations at the mooring location. The grey shading indicates the mean annual cycle \pm one standard deviation based on SeaWiFS and MODIS Aqua 8-day satellite chlorophyll for the period 1998 to 2012. The filled black circles are merged SeaWiFS/MODIS Aqua 8-day chlorophyll for 2010, the green line is the daily averaged $20 \mathrm{~m}$ in situ FLNTU chlorophyll and the red line is a 3-day smoothing of daily satellite data for 2010. The satellite data are averaged from all valid pixels in a $1^{\circ}(111 \mathrm{~km})$ square around the mooring location.

from a coupled physical-biogeochemical model, we evaluate the extent to which MRG waves, wind mixing and Wyrtki jet-induced entrainment of nutrients or chlorophyll, or both, contribute to the forcing of the chlorophyll variability.

\section{Methods}

\subsection{RAMA mooring observations}

A RAMA mooring was deployed on 22 May 2010 at $0.1^{\circ} \mathrm{N}$, $80.6^{\circ} \mathrm{E}$ and recovered on 16 December 2010 . The deployment was in oligotrophic waters about $800 \mathrm{~km}$ east of the potential influence of mesotrophic waters around the Maldives $\left(0.5^{\circ} \mathrm{N}, 73.5^{\circ} \mathrm{E}\right)$, which form part of the Chagos-Laccadive Ridge.

In addition to the standard RAMA mooring instrumentation, a combined chlorophyll fluorescence and backscatter sensor (FLNTU) manufactured by WETLabs (Philomath, Oregon, USA) was mounted at $25 \mathrm{~m}$ below the surface. The FLNTU chlorophyll excitation and emission wavelengths were 470 and $695 \mathrm{~nm}$, respectively. The backscatter wavelength was $700 \mathrm{~nm}$. For the gain settings used in this deployment, variability in the backscatter channel was barely detectable, so these data will not be discussed further. Fluorescence was converted to chlorophyll concentration using

$\operatorname{Chl}\left[\mathrm{mg} \mathrm{m}^{-3}\right]=$ scale factor $\times($ output - dark offset $)$, 
where output is the raw data from the instrument and scale factor $\left(0.0121\left[\mathrm{mg} \mathrm{m}^{-3}\right] /\right.$ count) and dark offset (50 counts) were from the instrument's factory calibration on 14 October 2009. In this context "counts" is simply a dimensionless number from the instrument between 0 and 4095 . This equation resulted in one negative daily mean chlorophyll concentration for the period of the deployment, so the dark count value was adjusted to 45 counts, bringing the time series of FLNTU chlorophyll into closer agreement with the satellite chlorophyll estimates from the vicinity of the mooring. Although this conversion from fluorescence to chlorophyll is only semiquantitative, we are less concerned with the absolute accuracy of the chlorophyll measurements than we are with their temporal variability.

Optical instruments are subject to fouling, but this sensor was fitted with a copper antifouling shutter and rubber wiper that are standard on most WETLabs instruments. We usually diagnose fouling as an increase in the baseline value, or noisy variability of the fluorescence or backscatter channels, or both. There was no increase in the baseline fluorescence values, although there was an increase in variability of the fluorescence channel (the chlorophyll spikes). This variance was periodic rather than noisy, which we interpret as real environmental variability. The mooring-observed increase in fluorescence variability is also confirmed by satellite chlorophyll observations. The sampling strategy for the sensor was to take five fluorescence readings at $1 \mathrm{~Hz}$ every $15 \mathrm{~min}$ for the duration of the deployment. The $1 \mathrm{~Hz}$ measurements were averaged to create a mean fluorescence value every $15 \mathrm{~min}$ and then a $24 \mathrm{~h}$ running mean was applied to produce the daily data plotted in Fig. 2 and elsewhere. We did not observe spikes in the $1 \mathrm{~Hz}$ data caused by, for example, suspended particles or colored dissolved organic matter.

We use the RAMA mooring data to investigate physical mechanisms driving chlorophyll variability at the mooring. As a guide to our interpretation, we calculated lagged correlations between the following pairs of parameters:

1. wind speed and temperature at $20 \mathrm{~m}$;

2. wind speed and chlorophyll at $25 \mathrm{~m}$;

3. zonal current speed $(u)$ at $10 \mathrm{~m}$ and chlorophyll at $25 \mathrm{~m}$;

4. meridional current speed $(v)$ at $10 \mathrm{~m}$ and chlorophyll at $25 \mathrm{~m}$

5. temperature at $20 \mathrm{~m}$ and chlorophyll at $25 \mathrm{~m}$;

6. salinity at $40 \mathrm{~m}$ and chlorophyll at $25 \mathrm{~m}$.

In addition, we also computed the autocorrelation function of chlorophyll at $25 \mathrm{~m}$.

In the "Results" section we summarize these correlations and their lags and use them to build a conceptual model of the physical drivers that lead to the increased chlorophyll in the second half of 2010, including the regular peaks observed.
We also performed the same cross-correlation analyses with model output.

\subsection{Satellite observations}

Satellite chlorophyll observations from both the SeaWiFS and the MODerate resolution Imaging Spectroradiometer (MODIS Aqua) were used to quantify the spatial and temporal chlorophyll variability in the vicinity of the mooring. To quantify the climatological seasonal cycle of chlorophyll in a $1^{\circ}$ latitude by $1^{\circ}$ longitude box centered on the mooring, all available 8-day average, $9 \mathrm{~km}$ SeaWiFS and MODIS data from 1 January 1998 to 31 December 2012 were averaged. This means that when both sensors were operating simultaneously, the two were averaged. This was the case most of the time from mid-2002 to late 2010. Similar time series of both 8-day and daily data were extracted for just 2010, for direct comparison with the moored fluorescence time series. We acknowledge possible differences between SeaWiFS and MODIS chlorophyll measurements but chose to average across sensors to increase spatial and temporal coverage in this cloudy environment. For 2010 we compared the SeaWiFS and MODIS retrievals for a large box around the mooring $\left(5^{\circ} \mathrm{S}\right.$ to $5^{\circ} \mathrm{N}, 70$ to $\left.90^{\circ} \mathrm{E}\right)$. There were two occasions where SeaWiFS Chl was about $0.1 \mathrm{mg} \mathrm{m}^{-3}$ greater than MODIS. Most of the time the difference between the two sensors was less than $0.05 \mathrm{mg} \mathrm{m}^{-3}$, and the average difference was only $0.02 \mathrm{mg} \mathrm{m}^{-3}$. In the same box $\left(5^{\circ} \mathrm{S}\right.$ to $5^{\circ} \mathrm{N}, 70$ to $\left.90^{\circ} \mathrm{E}\right)$, the percentage of valid pixels for MODIS in an 8-day period was about $10 \%$. For SeaWiFS it was slightly higher, and on four occasions in 2010 it exceeded $20 \%$.

MODIS seasonal climatologies of SST were obtained from NASA to depict the seasonal cycle for the central Indian Ocean. We use this potentially cloud-contaminated product because it is of higher spatial resolution than the microwave products and the seasonal climatologies average out the cloudiness. NOAA Optimum Interpolation (OI) version 2, daily SST data were used for producing a Hovmöller plot for 2010. We prefer the cloud-free microwave SST product when not producing climatologies. Likewise, Hovmuller plots of sea surface height anomaly (SSHA) and surface winds were produced from weekly Archiving, Validation and Interpretation of Satellite Oceanographic data (AVISO) mean sea level anomaly data and daily WindSat acquired from remotesensing systems, respectively. Currents were obtained from the OSCAR project (Ocean Surface Current Analysis Realtime; Bonjean and Lagerloef, 2002). These data are surface current speed and direction, derived from altimetry and scatterometry, and were used to produce animations for comparison with surface chlorophyll patterns.

\subsection{CARS and RG-Argo Climatologies}

The CSIRO Atlas of Regional Seas (CARS; http://www. marine.csiro.au/ dunn/cars2009/) is a gridded climatology 
of temperature, salinity, oxygen, nitrate, phosphate and silicate (Ridgway et al. 2002). The data used in the mapping include Argo data up to May 2009 and historical CTD (conductivity-temperature-depth) and bottle data collected between 1950 and 2008. Horizontal grid spacing is $0.5^{\circ}$ in latitude and longitude, and the data are mapped onto 79 depth levels between the surface and $5500 \mathrm{~m}$. The seasonal cycle in the climatology is fit with a sine and cosine wave to generate a full annual cycle. The oxygen and nutrient data that inform the climatology are patchy in space and time in some parts of the ocean. At our mooring location this issue is minimized by the close proximity of the WOCE (World Ocean Circulation Experiment) I8 repeat hydrography line. We used CARS 2009 to depict the seasonal cycle of salinity and nitrate with depth.

The Roemmich-Gilson Argo Climatology (RG-Argo: http://sio-argo.ucsd.edu/RG_Climatology.html) maps the temperature and salinity fields of Argo data from 2004 to 2011 into a monthly gridded product with grid spacing of $0.5^{\circ}$ in latitude and longitude over 58 pressure levels from the surface to $1975 \mathrm{dbar}$ (Roemmich and Gilson, 2009). We used this climatology and Argo data from individual floats in the vicinity of the mooring to describe the mean seasonal cycle of salinity with depth and also the 2010 time-depth variability.

\subsection{Biogeochemical modeling}

OFAM3 (Ocean Forecasting Australia Model, version 3) is a near-global, eddy-resolving, $z^{*}$ configuration of version 4.1 of the Modular Ocean Model (Griffies, 2009), developed principally for hindcasting and forecasting upper-ocean conditions in nonpolar regions. The key features of OFAM3 are described here, and a comprehensive technical description of OFAM3 is given in Oke et al. (2013). The model grid has $0.1^{\circ}$ latitude and longitude grid spacing between $75^{\circ} \mathrm{S}$ and $75^{\circ} \mathrm{N}$, with $5 \mathrm{~m}$ vertical resolution down to $40 \mathrm{~m}$ depth and $10 \mathrm{~m}$ vertical resolution to $200 \mathrm{~m}$ depth.

OFAM3 uses the vertical mixing scheme described by Chen et al. (1994), and a biharmonic Smagorinsky viscosity scheme described by Griffies and Hallberg (2000). The model is forced with $1.5^{\circ}$ resolution, 3-hourly surface heat, freshwater and momentum fluxes from ERA-Interim (Dee and Uppala, 2009). Surface temperature and salinity are restored to monthly averaged observations with a restoring timescale of 10 and 30 days, respectively.

OFAM3 includes a biogeochemical cycling model, called the Whole Ocean Model with Biogeochemistry and Trophicdynamics (WOMBAT). WOMBAT is a three-dimensional NPZD (nutrient, phytoplankton, zooplankton, detritus) model described by Kidston et al. (2011), with the addition of iron. In WOMBAT, phytoplankton growth is limited by light, phosphate and iron, with the minimum of these three terms limiting growth.
The model was initialized at rest, with potential temperature, salinity and biophysical fields from observational-based climatologies (Oke et al., 2013) and then integrated for 32 years, including an initial 14-year spin-up period followed by 18 years' simulation spanning the $1993-2010$ period. We present results from 2010.

\section{Results}

\subsection{Spatial context}

The seasonal variability of the equatorial Indian Ocean is strongly influenced by the monsoonal wind forcing. The northeast monsoon (boreal winter) is characterized by cold winds from the interior of the Indian continent blowing from the northwest across the northern Indian Ocean. During the southwest monsoon (boreal summer), the winds reverse and blow from the southwest toward the hot continent. Along the equator near $80^{\circ} \mathrm{E}$, the monsoon periods are characterized by very weak winds, but the monsoon transitions in April-May and October-November are characterized by strong eastward winds (Risien and Chelton, 2008). The annual mean wind stress at the equator is eastward, resulting in warm equatorial sea surface temperatures in contrast to the cool waters of the equatorial Atlantic and Pacific oceans that result from mean upwelling (Schott and McCreary, 2001).

The annual cycle of sea surface temperature is dominated by solar heating in the summer of each hemisphere, and by cooling through evaporative heat loss driven by monsoon winds, and by upwelling along the western side of the basin during the southwest (summer) monsoon (Rao and Sivakumar, 2000). The mean distribution of sea surface salinity is characterized by salty waters in regions dominated by evaporation: the southern hemisphere subtropics, Arabian Sea and Persian Gulf, and fresh waters in the Bay of Bengal and around Indonesia, where precipitation exceeds evaporation and river runoff is significant (Schott and McCreary, 2001). In January-April, low-salinity water from the Bay of Bengal moves westward into the western Arabian Sea. During March to September, the salty Arabian Sea waters extend eastward and southward (Rao and Sivakumar, 2003). Ocean currents along the equator near $80^{\circ} \mathrm{E}$ are weak during the monsoons, and the eastward-flowing south equatorial countercurrent is found just to the south of the equator during the winter monsoon. In the summer monsoon it is to the north of the equator. During the monsoon transitions the Wyrtki jets flow strongly eastward.

In Fig. 1 we show the seasonal variability in SST, surface salinity and surface chlorophyll for a large region encompassing the mooring on the equator at $80.5^{\circ} \mathrm{E}$. Sri Lanka and the southern tip of India are in the central north of each panel. On the eastern edge of each panel is Sumatra. The Maldives are just north of the equator at about $73^{\circ} \mathrm{E}$. In the northern hemisphere (boreal) winter, the Arabian Sea and Bay 
of Bengal are relatively cool, and warm SSTs spread from Sumatra, linking the central Indian Ocean with the Indonesian warm pool. Surface currents are very weak (Fig. 1a). The Bay of Bengal is relatively fresh and the high-salinity waters of the Arabian Sea are confined to the northwest Indian Ocean (Fig. 1b). Low chlorophyll concentrations span most of the equatorial Indian Ocean, and the predominantly westward surface currents in the northwest of the region (Fig. 1a) are visible as a wake of elevated chlorophyll to the west of the Maldives (Fig. 1c). SSTs become even warmer in boreal spring, and waters of about $30^{\circ} \mathrm{C}$ span the entire equatorial Indian Ocean. The eastward Wyrtki jets are strongest west of the mooring and weaker to the east (Fig. 1d). The Bay of Bengal remains fresh, but the salty waters of the western Indian Ocean are expanding eastward and southward with a pronounced equatorial tongue of higher salinity (Fig. 1e). Basin-wide chlorophyll concentrations remain low and the higher chlorophyll around the Maldives has largely disappeared (Fig. 1f). In boreal summer, wind-driven upwelling off Somalia and the Horn of Africa together with monsoonal wind mixing cools SSTs in the Arabian Sea, while in the southern Indian Ocean, the Southern Hemisphere winter also cools the temperate and subtropical ocean. The southward meander in the South Equatorial Countercurrent brings relatively weak eastward flow across the mooring (Fig. 1g). The western Indian Ocean becomes more broadly saline and the western Bay of Bengal becomes slightly saltier than in spring (Fig. 1h). The elevated productivity from the Arabian Sea upwelling system is visible in the far northwest of this region, as is elevated chlorophyll around Sri Lanka and the southern tip of India (Fig. 1i). This is around the time that chlorophyll concentrations at our RAMA mooring site began to increase (Fig. 2). In boreal autumn the warmer SSTs along the equator begin to expand poleward (Fig. 1j), the highest-salinity water from the Arabian Sea is closest to the mooring site (Fig. 1k) and there is clear evidence for high chlorophyll from around the Maldives being advected eastward towards, but just north of the mooring (Fig. 11).

\subsection{Mooring time series}

The time series of chlorophyll measured by the FLNTU on the mooring is shown in Fig. 2, along with satellite-derived time series for 2010 and the satellite-based climatology. The main feature of note in the FLNTU data is the increase in mean chlorophyll concentration and its temporal variability beginning in October. The 2010 satellite data are shown at two temporal resolutions: the standard 8-day NASA product (filled black circles) and a 3-day running mean of daily data (red line). For the climatology, the broadening of the standard deviation envelope suggests that the increases in both the mean chlorophyll and its variability in the latter part of 2010 are regular features at this location. Indeed, the interannual time series (not shown) show that chlorophyll spikes
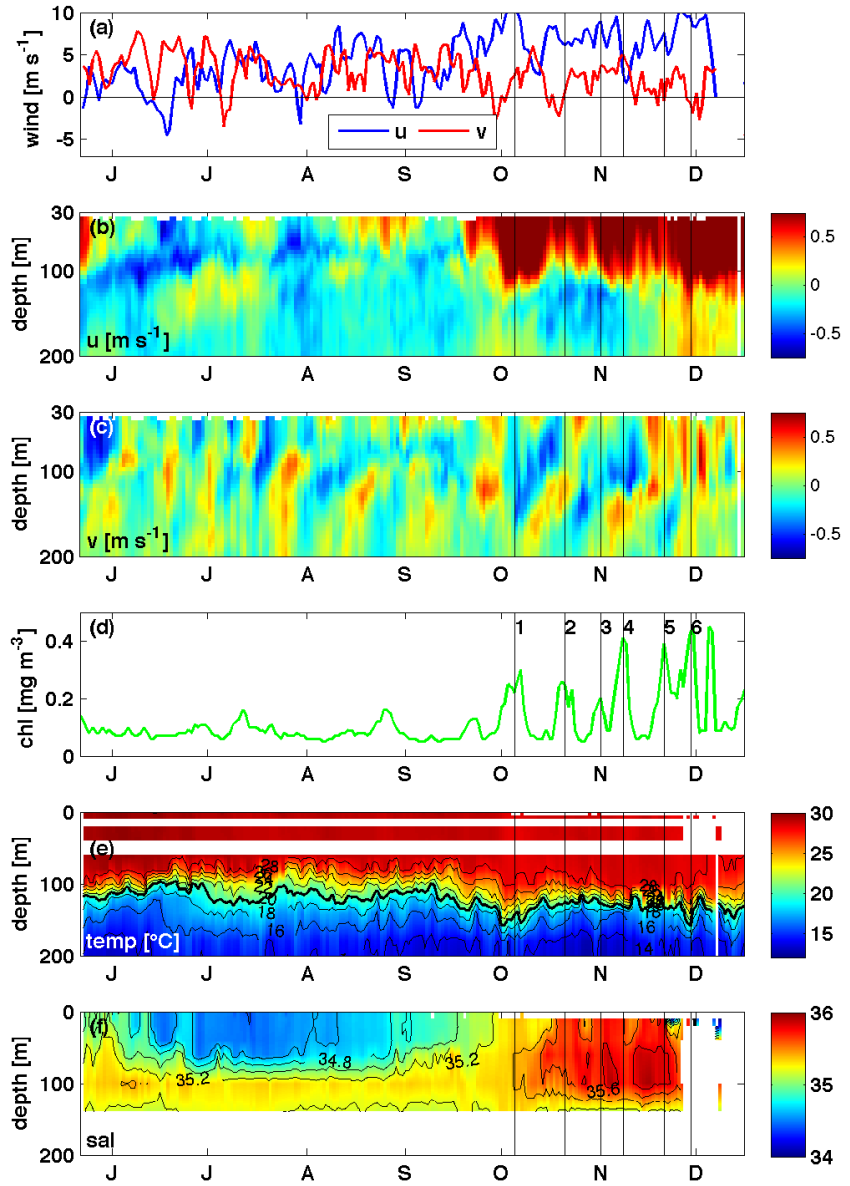

Figure 3. Time series of mooring physical and biological parameters. (a) Zonal $\left(u, \mathrm{~m} \mathrm{~s}^{-1}\right)$ and meridional $\left(v, \mathrm{~ms}^{-1}\right)$ winds; (b) zonal $\left(u, \mathrm{~m} \mathrm{~s}^{-1}\right)$ current; (c) meridional $\left(v, \mathrm{~m} \mathrm{~s}^{-1}\right)$ current; (d) chlorophyll concentration $\left(\mathrm{mg} \mathrm{m}^{-3}\right)$ from the moored fluorometer; (e) temperature $\left(T,{ }^{\circ} \mathrm{C}\right)$ with $20^{\circ} \mathrm{C}$ contour in bold; (f) salinity. Gaps in the $T$ and $S$ data are due to sensor failure. Vertical black lines in each panel indicate the six main chlorophyll peaks during October to December, which are numbered in panel (d).

during boreal fall in this region are observed in $60-75 \%$ of years.

Figure 3 puts the chlorophyll time series in perspective with the physical data collected at the mooring. Over the boreal summer to winter period, the low-frequency variability in the equatorial winds measured at the mooring location (Fig. 3a) is dominated by a general increase in the zonal wind beginning in mid-September. This increase is associated with the development of the Wyrtki jets (Schott and McCreary, 2001). A small tendency towards southward flow is also observed at this time in the meridional winds. An increase in zonal currents in the upper $100 \mathrm{~m}$ (the Wyrtki jets, Fig. 3b) is evident in response to the increasing zonal wind speed, and this eastward flow gradually deepens from mid-September to December. Meridional velocity is characterized by an approximately 2 -week periodicity with upward phase propaga- 

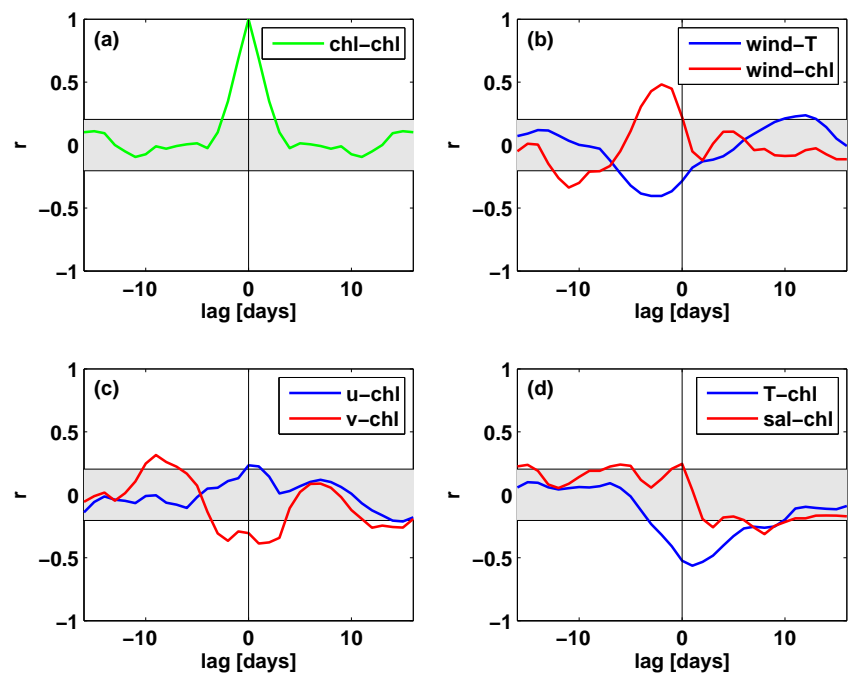

Figure 4. Cross-correlation analyses of physical parameters and chlorophyll from the RAMA mooring at $0^{\circ}, 80.5^{\circ} \mathrm{E}$. In the figure legends, the first-named parameter leads the second-named, so, for example, the strong positive peak in wind speed and $\mathrm{Chl}$ in panel (b) means that stronger winds are followed by increased chlorophyll about 2-3 days later. The cross-correlation analysis was performed for the section of the data set where the chlorophyll spikes were most obvious: 15 September to 15 December 2010. The shaded region in each panel indicates the $95 \%$ confidence interval.

tion that is particularly evident from August through November (Fig. 3c). This biweekly periodicity in the meridional velocities with upward phase propagation indicates the presence of MRG waves (Prasanna Kumar et al., 2012). These waves are present throughout the year and also at other locations along the equator.

The second, third and fourth peaks in chlorophyll (Fig. 3d) coincide with the surface expression of these vertically propagating features in the meridional velocity field through midNovember. Subsequently there is a shift to more persistent southward flow between $30 \mathrm{~m}$ and $100 \mathrm{~m}$. Near-surface salinity, which decreased from June to mid-July, increases from mid-August through to mid-November, and then begins to decrease again (Fig. 3f).

The cross-correlation plots in Fig. 4 are used to reveal potential drivers of the increased chlorophyll concentrations. The correlation analysis was performed only for the period 15 September 2010 to 15 December 2010, when the peaks in chlorophyll are observed. The chlorophyll autocorrelation peak at 0 days' lag is quite sharp (Fig. 4a), indicating that the peaks last for only a few days. There is a small negative but not statistically significant correlation at about 2 weeks. The cross-correlations between wind and chlorophyll and between temperature and chlorophyll (Fig. 4b) show that increased winds lead both cooler temperature and increased chlorophyll by about 3 days. This could be indicative of mixing or entrainment from below, which we will discuss later.

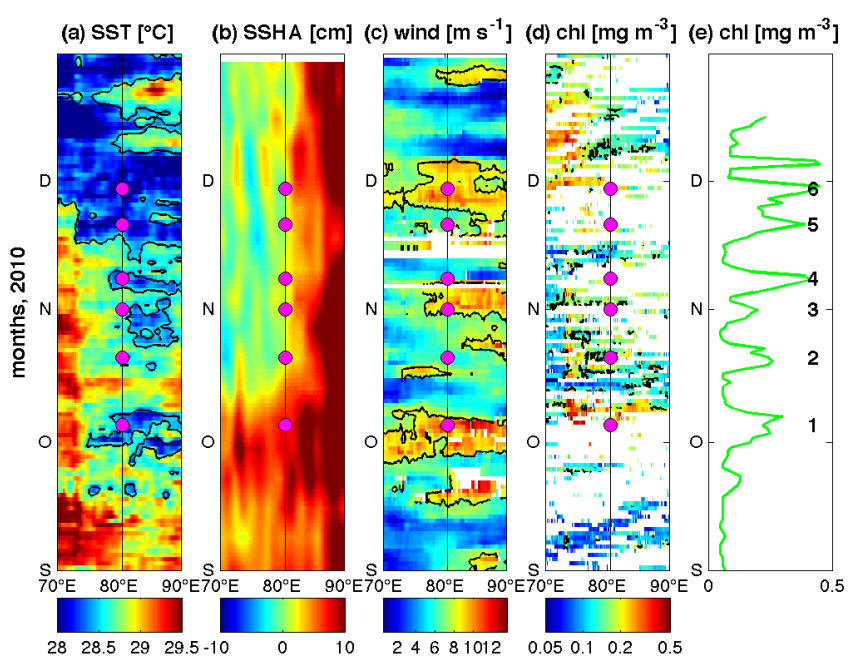

Figure 5. Hovmuller plots of remotely sensed observations along the equator centered at the mooring location: (a) microwave optimally interpolated SST; (b) SSH anomaly from AVISO; (c) wind speed from WindSat and (d) satellite chlorophyll from MODIS and SeaWiFS combined. Panel (e) is the fluorometer time series from the mooring, at $25 \mathrm{~m}$ depth. Black contours in the Hovmuller plots are $28.5^{\circ} \mathrm{C}$ in (a), $8 \mathrm{~m} \mathrm{~s}^{-1}$ in (c) and $0.15 \mathrm{mg} \mathrm{m}^{-3}$ in (d). The numbers in (e) indicate six major chlorophyll peaks observed at the mooring.

The correlations between currents and chlorophyll (Fig. 4c) reveal a weak and only marginally significant relationship for zonal currents near zero lag. For meridional currents there is a broad peak of negative correlation around 0 days and a positive peak at around -9 days. MRG waves are influencing this correlation structure, as evident in the biweekly periodicity of the cross-correlation. However, if MRG waves were simply advecting chlorophyll past the mooring site, meridional velocity would lead Chl by half a cycle or 3.5 days and we would expect the observed correlation structure to peak at this lead time. Finally, Fig. 4d shows that cool temperatures are correlated with higher chlorophyll around zero lag, but there is no significant correlation between salinity and chlorophyll.

\subsection{Satellite and Argo analysis}

The Hovmuller plot (Fig. 5) provides a time-longitude context for the observations. Six peaks occur around 6 and 20 October and 1, 8, 21 and 29 November (Fig. 5e). There is no propagating west to east signal that could be identified in contours of the $28.5^{\circ} \mathrm{C}$ isotherm (Fig. 5a), the $8 \mathrm{~m} \mathrm{~s}^{-1}$ wind contour (Fig. 5c) or by eye in the SSHA plot (Fig. 5b). When the chlorophyll data are not smoothed in time and space, the cloud contamination is such that it is difficult to observe any spatial patterns.

The Hovmuller plots (Fig. 5) and an animation of satellite chlorophyll and OSCAR current velocities for the region 


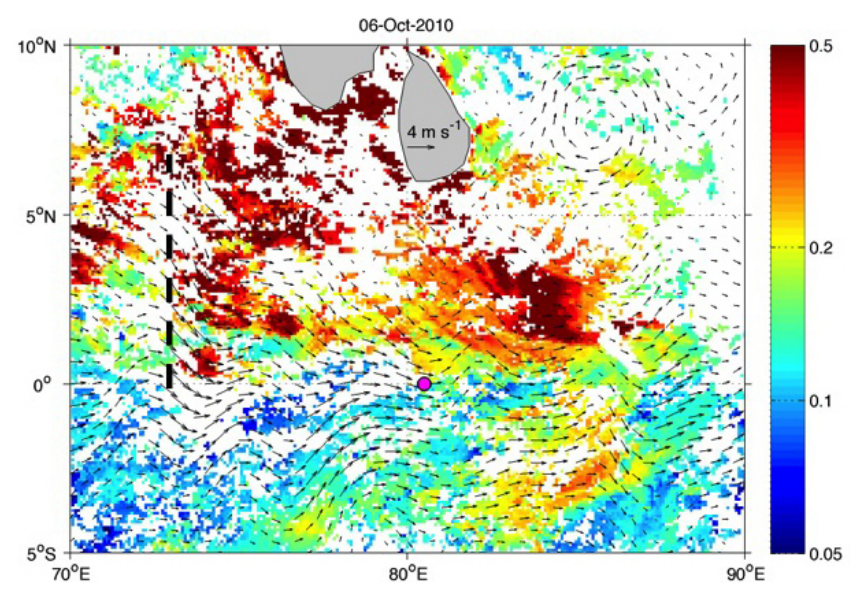

Figure 6. Chlorophyll map created from a 15-day average of MODIS Aqua data centered on 6 October 2010 (peak 1 in Fig. 5). The mooring on the equator at $80.5^{\circ} \mathrm{E}$ is marked with a magenta circle. Vectors are OSCAR geostrophic currents calculated from satellite altimetry and scatterometry for a 5-day period centered on 1 October 2010. The figure illustrates the high chlorophyll from the Maldives $\left(\sim 73^{\circ} \mathrm{E}\right)$ being advected eastwards by the large-scale flow and southwards towards the mooring by wave processes. At the resolution of this coastline, it is not possible to see the Maldives, so we have indicated their location with a thick dashed line.

(see Supplement chl_oscar.m4v) suggest that advection of chlorophyll from north of the mooring may be important in the formation of the chlorophyll peaks at the equator. This advection is illustrated in Fig. 6, which is a snapshot from the chlorophyll animation for 6 October 2010 with surface geostrophic currents derived from sea surface height data superimposed. The chlorophyll data shown are a 15-day average centered on 6 October, with 5-day average vectors centered on 1 October from the OSCAR product. The Maldives and the Chagos-Laccadive Ridge are in a north-south line at approximately $73^{\circ} \mathrm{E}$. It is clear that high chlorophyll is being generated in the region of the Maldives, and the patterns indicate a sweeping of that feature towards the equator. Note also the meridional meandering that is apparent in the current field. It is unlikely that this is an MRG wave though because the wavelength of $500 \mathrm{~km}$ is too short (it should be 3000 to $4500 \mathrm{~km}$ according to Sengupta et al., 2004).

The seasonal cycle of surface salinity (Fig. 1) and the time series of salinity observed at the mooring site (Fig. 3) indicate the arrival of high-salinity water at the mooring with the onset of the fall Wyrtki jets. To determine whether or not this is a regular feature, we examined the salinity fields in the CARS and RG-Argo atlases. Figure 7 shows timedepth sections of salinity from the CARS long-term mean, and from RG-Argo for 2010 and for the 8-year average 20042011. These plots clearly show elevated salinity in the latter part of the calendar year between 25 and $125 \mathrm{~m}$, overlying lower-salinity water that persists year-round. In CARS, the surface water remains fresh during the arrival of the sub-

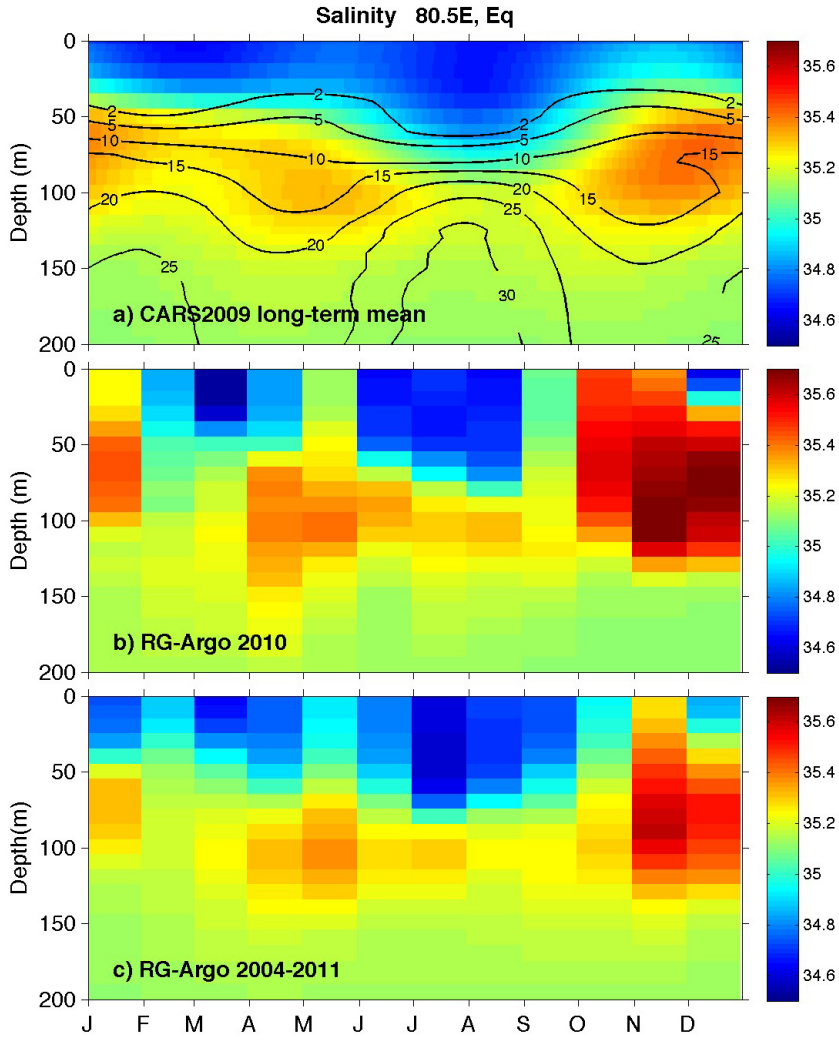

Figure 7. Time-depth sections of salinity (PSS-78) for the mooring location. (a) The long-term mean from CARS with nitrate (mmol $\mathrm{m}^{-3}$ ), also from CARS contoured; (b) the RG-Argo product for 2010; (c) the RG-Argo climatology based on data from 2004 to 2011.

surface salinity peak. In RG-Argo, high salinities reach the surface in November in all years and in October as well in 2010. The high-salinity waters are more saline in RG-Argo than in CARS, and they are more saline in 2010 compared with the 8-year average of RG-Argo (perhaps because 2010 was a negative IOD year). Since there is fresh water below the high-salinity layer, this suggests that zonal currents advect the high-salinity water eastward at thermocline depth, where it is then entrained into the mixed layer by local windgenerated turbulence. Associated with the arrival of highsalinity water and with the onset of both the spring and fall Wyrtki jets, the nitricline in CARS also shoals. The timing of the high salinity at the mooring, coinciding with the elevated chlorophyll at the mooring implies both advection of water from the west by Wyrtki jets and entrainment by local mixing. 


\section{Discussion}

Based on the patterns in the data, and incorporating some model results, we evaluate two hypotheses to explain the chlorophyll spikes from October to December 2010:

1. Enhanced horizontal advection brings high chlorophyll concentrations, generated near the Maldives, into the convergent equatorial zone from the north.

2. Wind stirring and Wyrtki jet-induced shear across the base of the mixed layer favors entrainment of nutrients and/or chlorophyll from depth.

Previous studies supporting the first hypothesis include a study by Sasamal (2007) which showed that westward flow through the Maldive Islands enhances biological productivity over a large area west of the Maldives during boreal winter. This was visualized with MODIS chlorophyll from 11 December 2003. Monthly climatologies of surface chlorophyll derived from SeaWiFS show that this enhanced biological production extends eastward from the Maldives (and the Chagos-Laccadive Ridge, in general) during October and November, when the fall Wyrtki jets are well-developed and that these effects extend to $80.5^{\circ} \mathrm{E}$ and beyond (Fig. 1).

Previous studies supporting the second hypothesis include observations of intense surface cooling of the southern tropical Indian Ocean at intraseasonal timescales during austral summer (Vinayachandran and Saji, 2008). Temperature profiles from Argo floats within the cooling region show evidence for the entrainment of cool thermocline water into the mixed layer, and the cooling events are accompanied by increases in surface chlorophyll, which provides additional evidence for entrainment (Vinayachandran and Saji, 2008). Similarly, using satellite observations and biophysical ocean simulations, Resplandy et al. (2009) showed that seasonal and intraseasonal fluctuations in satellite-measured chlorophyll concentrations (in austral winter and during MJO events, respectively) correspond to wind-induced mixing episodes.

\subsection{Evaluation of hypotheses based on observations}

The feature that we are most interested in explaining is the series of spikes in the moored chlorophyll record from September through December 2010 (Fig. 2). These spikes are also partly visible in the daily satellite chlorophyll data, although gaps due to clouds prohibit the daily satellite observations from more accurately capturing the variability. As we go to 8-day averaged satellite chlorophyll, the spikes are barely evident. However, an important distinction between the in situ and satellite-based chlorophyll estimates is that the 8day satellite data show higher baseline chlorophyll concentrations, suggesting a driving process that occurs relatively consistently over the time period. In contrast, the in situ measurements show little to no increase in the baseline low chlorophyll values over October to December compared to
June through October. The consistent baseline indicates that there was no biofouling of the fluorometer during this period. It also indicates that the chlorophyll variability that gives rise to elevated mean values is associated with distinct event forcing that does not persist between events. Therefore the difference between the mooring and 8-day satellite data is due to the averaging.

The right-hand column of Fig. 1 and the snapshot of chlorophyll in Fig. 6 both clearly show that the interaction of the large-scale flow with the Chagos-Laccadive Ridge generates high chlorophyll that is advected towards the east in the second half of the calendar year. During boreal winter the advection of high chlorophyll is to the west, and the spring seems to be a period of transition. Island effects such as this are commonly observed in other parts of the world, such as in the wake of the Galapagos and Marquesas islands in the Pacific (Legeckis et al., 2004) and Kerguelen and Crozet islands in the Southern Ocean (Blain et al., 2007). The stimulation of chlorophyll occurs because the passage of the currents past an obstacle induces vertical and horizontal mixing, and in the Pacific and Southern ocean examples just mentioned, the crustal material of the islands acts as a source of the limiting nutrient iron to the surface ocean.

However, two lines of evidence suggest that the pulses of high chlorophyll observed at the mooring are not simply advected from the vicinity of the Maldives. The first is the time required for a water parcel to move from the Maldives at $73.25^{\circ} \mathrm{E}$ to the mooring at $80.5^{\circ} \mathrm{E}$, a distance of $805 \mathrm{~km}$. If the chlorophyll data in the Hovmuller diagram (Fig. 5d) are spatially and temporally smoothed, it is possible to identify five eastward-propagating chlorophyll peaks and draw a line through each of them. The slope of the lines is equivalent to a mean propagation speed of $1.95 \pm 0.33 \mathrm{~m} \mathrm{~s}^{-1}$. Is it feasible that local currents could advect high chlorophyll features at this speed? Schott and McCreary (2001, their Fig. 22) reported eastward velocities as high as $1.5 \mathrm{~m} \mathrm{~s}^{-1}$ in early November 1993, but most of the time the speed of the Wyrtki jets was $1 \mathrm{~m} \mathrm{~s}^{-1}$ or less. Mean zonal and meridional velocities at $10 \mathrm{~m}$ at the mooring during the time periods of the four chlorophyll peaks were 0.97 and $-0.29 \mathrm{~m} \mathrm{~s}^{-1}$, respectively (Fig. 3). Including only the upper quartile of velocity events over this period increases average zonal current speed to $1.2 \mathrm{~m} \mathrm{~s}^{-1}$, which is still too slow. Therefore, we conclude that the observed velocities both during our deployment and in previous studies are almost half what they would need to be for chlorophyll peaks initiated at the Maldives to be advected to the mooring. The very weak correlation between zonal velocity and chlorophyll (Fig. 4) is consistent with these arguments. The second line of evidence arguing against simply eastward propagation of the island wake high chlorophyll into the vicinity of the mooring is that the Maldives and the trailing high chlorophyll occur slightly north of the equator. We require a mechanism that moves the high chlorophyll southwards to the equator. We now explore wave 
processes that might be responsible for this southward advection.

The association of the chlorophyll peaks with a southward meridional flow (Fig. 4c) rules out Kelvin waves as a source since they are associated with zero meridional velocity. MRG waves have maximum meridional velocity on the equator and biweekly periodicity (Sengupta et al., 2004). The factors controlling the generation and propagation of MRG waves in the central and eastern Indian Ocean were examined in theoretical, idealized and realistic ocean models in Miyama et al. (2006). They concluded that the presence of a shallow pycnocline is an essential concentrating factor that leads to wave reflection off the sea surface and pycnocline, leading to the eastward intensification of the wave signal as measured in meridional velocity along the equator. They also suggested that in the central Indian Ocean, the strength of the MRG variability is induced by wind stress variability. Their results did not, however, include the influence of the Maldive Ridge. While the ridge is present in their general circulation model, smoothing of bathymetry in models generally reduces the impact of steep topography.

We propose that as the Wyrtki jets hit the Maldive Ridge, island wake effects generate mixing (likely both vertical and horizontal) and elevated chlorophyll that is then advected eastward by the Wyrtki jet. MRG waves superimposed on this pattern could advect high chlorophyll from just north of the equator into the vicinity of the mooring. These MRG waves are forced by meridional wind stress variations of similar period (Chatterjee and Goswami, 2004). The current vectors overlaid on Fig. 6 show a meandering wave-like structure similar to the Wyrtki jet near the time of peak 1 centered on 6 October 2010 (Fig. 5). However, whether this meander is associated with an MRG wave is debatable. The expected zonal wavelength for biweekly MRG waves is 3000$4500 \mathrm{~km}$, whereas the zonal wavelength evident in Fig. 6 is only $500 \mathrm{~km}$. Importantly, boreal spring Wyrtki jets do not seem to display a similar pattern of chlorophyll variability. This is despite the climatological data (Fig. 7a) showing that the nutricline is as shallow in April and May as it is in November. During this time period the large-scale currents are in transition and there is no large island wake feature east of the Maldives containing high chlorophyll (Fig. 1f).

We now turn to our second hypothesis, namely vertical turbulence generated by winds or Wyrtki jet-induced shear instability across the base of the mixed layer, or both. If these processes occur, they would favor vertical entrainment of nutrients or chlorophyll or both from the thermocline. This idea is supported by a positive correlation between wind speed and chlorophyll and a negative correlation between wind speed and mixed layer temperature (Fig. 4b). In both cases, the wind perturbation leads the temperature or chlorophyll response by a few days, consistent with the timescales required for mixing and a phytoplankton response. There is also a considerable amount of synoptic-scale variability in the winds that is amplified when wind speed is converted
Zonal Winds, Wind Stirring and $\mathrm{Chl}$ at $0^{\circ}, 80.5^{\circ} \mathrm{E}$
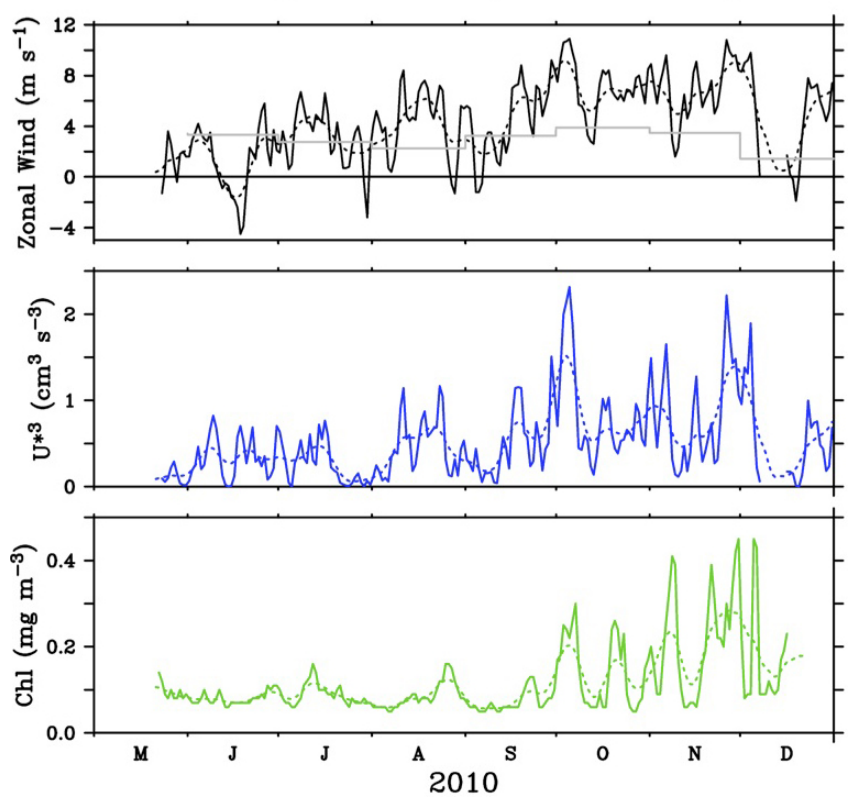

Figure 8. A closer look at winds and chlorophyll at the mooring location. Top panel is daily average zonal wind speed $\left(\mathrm{m} \mathrm{s}^{-1}\right.$; solid black line) overplotted on climatological monthly mean wind speed (grey line). Middle panel is daily average friction velocity cubed $\left(\mathrm{cm}^{3} \mathrm{~s}^{-3}\right)$, which is a measure of wind-induced turbulence generation ("wind stirring") in the mixed layer. Friction velocity is defined as $\left|\tau / \rho_{0}\right|^{1 / 2}$, where $\tau$ is surface wind stress magnitude and $\rho_{0}$ is the density of sea water. Bottom panel is the daily average of mooring chlorophyll fluorescence measurements $\left(\mathrm{mg} \mathrm{m}^{-3}\right)$. Dashed lines are daily data smoothed with a moving 13-day triangle filter, which is equivalent to a weekly average.

into parameters relevant to mixed layer turbulence generation. In addition, intraseasonal westerly wind variations evident in Fig. 8a are superimposed on unusually strong seasonal mean westerlies associated with the 2010 negative IOD event, boosting the mechanical energy available for mixing. The phasing and amplitude of the relationship between the cube of the wind friction velocity $\left(U^{* 3}\right.$; Fig. $\left.8 \mathrm{~b}\right)$ and chlorophyll (Fig. 8c) is exactly what is expected if the chlorophyll spikes are the result of entrainment events that are driven by synoptic zonal wind events (Fig. 8). The smoothed weekly average chlorophyll and $U^{* 3}$ data show the relationship even more clearly than the daily data. The correlation between daily $U^{* 3}$ and chlorophyll during the period mid-September to mid-December is 0.55 , with $U^{* 3}$ leading by about 2 days.

There is also a significant negative correlation between temperature and chlorophyll with zero lag (Fig. 4), indicating that cool temperatures co-occur with elevated chlorophyll. In general, shear and the inverse of the Richardson number $\left(\mathrm{Ri}^{-1}\right.$, data not shown) are higher during the Wyrtki jet period so this would establish a background to support entrainment. One possibility is that the MRG waves could contribute to vertical shear across the base of the mixed 

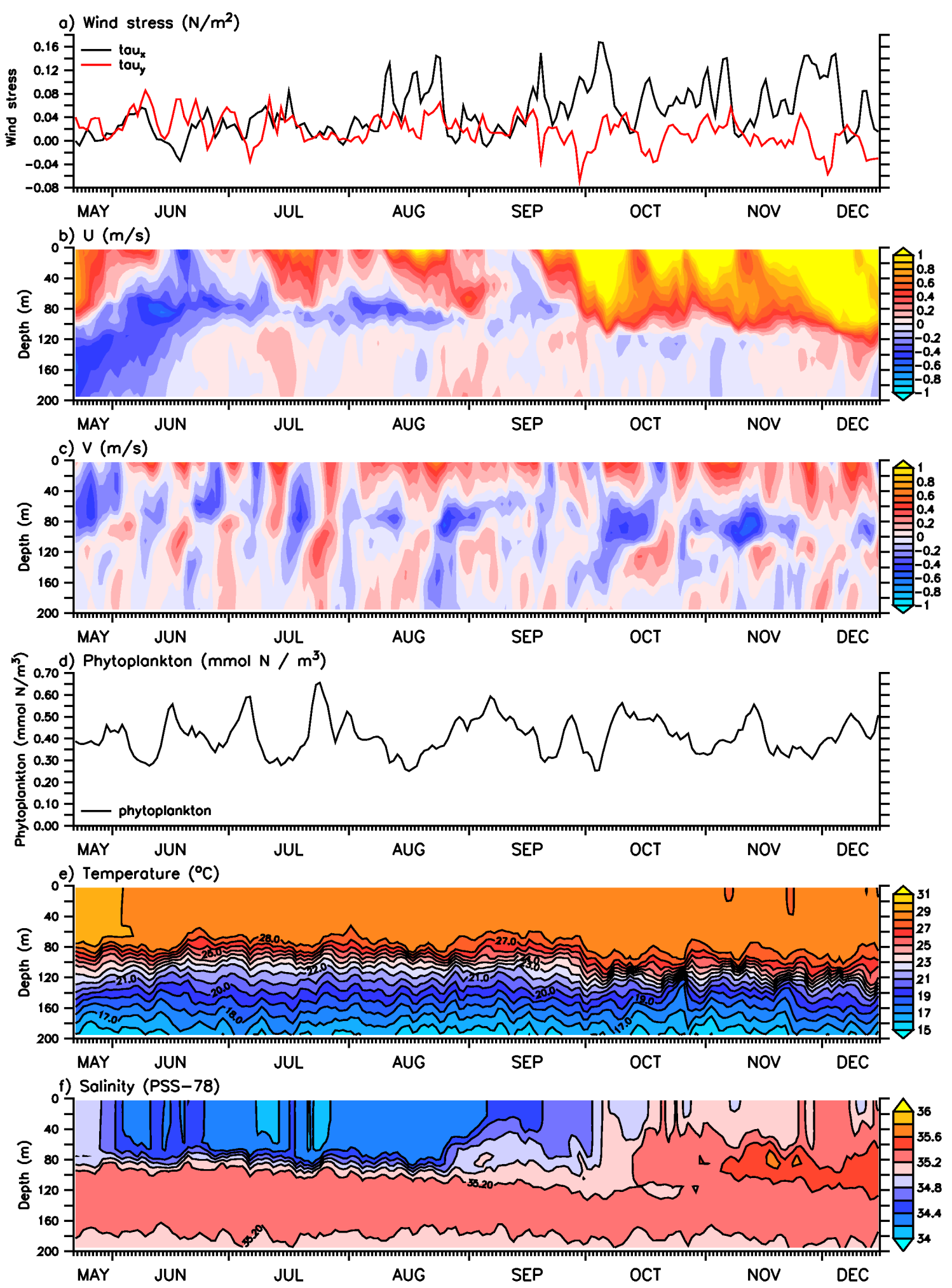

Figure 9. Simulation of parameters at the mooring site from OFAM3 model output. Panels from top to bottom: zonal (black) and meridional (red) components of wind stress $\left(\mathrm{N} \mathrm{m}^{-2}\right)$; zonal current velocity $\left(\mathrm{m} \mathrm{s}^{-1}\right)$; meridional current velocity $\left(\mathrm{m} \mathrm{s}^{-1}\right)$; phytoplankton $\left(\mathrm{mmol} \mathrm{N} \mathrm{m}^{-3}\right)$; temperature $\left({ }^{\circ} \mathrm{C}\right)$; salinity (PSS-78). 


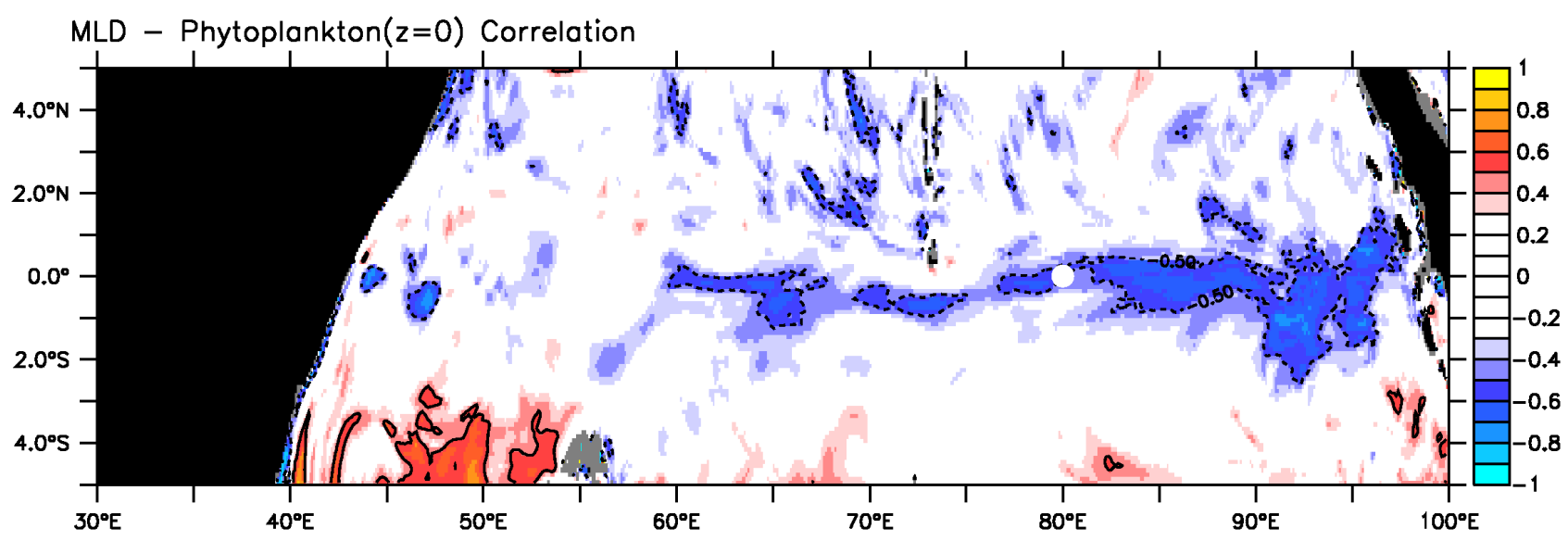

Figure 10. The correlation between mixed layer depth and phytoplankton concentration in the OFAM3 model. The mooring is marked with a white circle.

layer, which could enhance this entrainment via horizontal advection. However, a close look at the relationship between biweekly variations in $\mathrm{Ri}^{-1}$ and chlorophyll reveals that the phasing is random: sometimes one leads, sometimes the other. This suggests that the biweekly wave-shear-driven entrainment may contribute but is not the dominant control on the chlorophyll spikes.

This evidence argues for an explanation in which the largescale circulation (namely the Wyrtki jet with biweekly waves superimposed) creates high shears across the base of the mixed layer that favor entrainment, but the detailed timing of the chlorophyll spikes is keyed to a combination of synoptic wind events that generate additional turbulence though wind stirring $\left(U^{* 3}\right)$ and to meridional advection of a chlorophyll gradient. In the Hovmuller plot (Fig. 5), increases in wind speed are seen across a broad range of longitudes at the same time as the initiation of at least three of the chlorophyll peaks (Fig. 5c and e). However, local stirring associated with wind mixing cannot explain the propagation of the anomalies from the Maldive Ridge. That is, the wind bursts do not propagate, and in the case of peak 2 , there is only a very small wind perturbation.

\subsection{Evaluation of hypotheses based on model results}

To help assess the two hypotheses and provide some spatial perspective to our analysis, we use the OFAM3 simulations described in the "Methods" section and in Oke et al. (2013). To assess the realism of the simulation, we compare it to the observations from the mooring site shown in Fig. 3. The simulated current structure in the upper ocean is similar to the observations (Fig. 9). With the onset of the wind bursts in mid-September, a strong eastward current develops in the upper $100 \mathrm{~m}$, which accelerates during wind bursts, consistent with the observations. For the meridional currents, southward subsurface flow develops around $80 \mathrm{~m}$ in both October and November, which shoals with time consistent with the MRG wave signatures that can be seen in the observations (Fig. 3c) but is weaker. The simulation also shows that in the upper $30 \mathrm{~m}$, the flow is generally northward during the September to December period but there are short periods when surface flow either weakens or reverses. The flow in the upper $30 \mathrm{~m}$ of the water column is not resolved by the mooring observations.

The surface waters cool over the latter half of 2010, with a layer of well-mixed temperatures deepening from 60 to $80 \mathrm{~m}$ over the September to December period. The simulated surface water gets saltier, and a subsurface salinity maximum develops around $100 \mathrm{~m}$ from mid-October onward. Both features are evident in the observations (Fig. 3). Given that the model's physical behavior at the mooring site reflects many of the features evident in the observations, we were motivated to use the model to investigate the phytoplankton response observed at the mooring site.

Modeled phytoplankton concentrations at the mooring site are generally too high and have a different character compared to the spiky features observed in the mooring data. This partly reflects the simulation having too much nitrate (and other nutrients) in the upper ocean and the phytoplankton not being nutrient limited. A fixed carbon-to-chlorophyll ratio of $50: 1$ and $\mathrm{C}: \mathrm{N}$ of $106: 16$ gives 1.59 scaling for simulated $\mathrm{N} \mathrm{mmol} \mathrm{m}^{-3}$ to $\mathrm{mg} \mathrm{Chl} a \mathrm{~m}^{-3}$. The tendency of OFAM3 to overestimate the phytoplankton concentrations is a common bias in the simulation in the mid- and low latitudes and reflects the choice of model parameters used (Oke et al., 2013). While the phytoplankton concentrations are too high and lack a subsurface chlorophyll maximum that we would expect in this region, the model time series still exhibits realistic variability.

Simulated phytoplankton concentrations at the mooring site show a significant correlation with the zonal winds; this is of opposite sign to the observations (data not shown). In the simulation, the wind bursts are associated with a deepening of the mixed layer and a decline in phytoplankton 
as the high-phytoplankton surface water is mixed with lowphytoplankton deep water. This behavior is consistent with the hypothesis that westerly wind bursts drive enhanced vertical mixing (hypothesis 2). To support this hypothesis the simulation shows a significant negative phytoplankton-mixed layer depth correlation that occurs along a narrow band on the equator where the wind bursts are most active (Fig. 10). However, this negative phytoplankton-mixed layer depth correlation in the model could also be caused by wind-induced downwelling, depression of the nutricline and suppression of phytoplankton growth. This second interpretation is consistent with the simulation results and the interpretation in Wiggert et al. (2006). The correlation pattern in Fig. 10 is also consistent with the large-scale eastward-intensified wind- and current-induced downwelling that is observed in eastern Indian Ocean equatorial waters during this time period (Wiggert et al., 2006). Regardless, both models are inconsistent with our mooring-derived positive correlations between zonal winds and phytoplankton concentrations.

Model-derived animations of the mixed layer depth variability demonstrate that the features along the equator are complex (see Supplement animation mld_mov.gif). There are mixing and downwelling events that propagate rapidly across the basin (in less than 1 week), constrained to the narrow equatorial band where mixed layer depth and phytoplankton are negatively correlated. The movie also shows meandering currents that sweep surface waters across the Chagos-Laccadive Ridge into the narrow equatorial band and north-south movements in the mixed layer depth with time. These north-south excursions, coupled with a strong meridional gradient in phytoplankton, further modulate the phytoplankton variability. Both the variability and the shoaling patterns in meridional velocity suggest that MRG waves are present in the simulation, which is consistent with hypothesis 1 .

The simulations reveal that the mooring is located in a complex environment where both enhanced vertical mixing or downwelling, or both, associated with westerly wind bursts and north-south excursions associated with MRG waves play a role in the phytoplankton variability. Additional observations to the north and south of the mooring are needed to determine which mode is dominating the phytoplankton variability.

\section{Conclusions}

Time-series measurements of near-surface chlorophyll concentration from a mooring that was deployed at $80.5^{\circ} \mathrm{E}$ on the equator in the Indian Ocean in 2010 reveal several striking spikes in chlorophyll in October through December, at approximately 2-week intervals, that are associated with the development of the fall Wyrtki jet. Climatological satellite chlorophyll data as well as the interannual time series (not shown) show that chlorophyll spikes during boreal fall in this region are observed in $60-75 \%$ of years and so are likely reflective of recurring large-scale circulation-induced productivity enhancement in the central equatorial Indian Ocean.

These elevated chlorophyll concentrations are observed in spite of mean downwelling conditions, which in previous modeling studies have been associated with lower productivity. Satellite chlorophyll data also reveal increases in chlorophyll concentration north of the mooring location in October through December, caused by the interaction of the large-scale zonal currents with the Chagos-Laccadive Ridge and island wake effects. Our analysis suggests that the strong temporal variability in chlorophyll concentrations at the mooring location on the timescale of weeks is caused, at least in part, by local entrainment that is driven by synoptic zonal wind events. Energetic wind-forced MRG waves are ubiquitous in our mooring time-series record and might be expected to play a role in the Chl variability that we observe. However, from our statistical analysis and model simulations, we conclude that entrainment mixing may dominate. Our results both reveal and help to explain biogeochemical variability in a poorly understood part of the global ocean. However, additional observations are needed to fully quantify the relative importance of local versus remote forcing mechanisms.

It will be important to better understand the generation of these large chlorophyll features because of their differing implications for basin biogeochemistry and primary production. If equatorial chlorophyll spikes are due to MRG waves moving a meridional chlorophyll gradient across the equator, then there is no new primary production or carbon export associated with these large features. However, if the chlorophyll spikes are generated as a result of vertical mixing and entrainment, then they represent a source of primary productivity in an otherwise oligotrophic region and may have implications for carbon export and fisheries.

\section{The Supplement related to this article is available online at doi:10.5194/bg-12-2367-2015-supplement.}

Acknowledgements. P. G. Strutton is supported by the Australian Research Council's Future Fellow scheme and the Centre of Excellence for Climate System Science. H. E. Phillips is supported by the Australian Research Council's Discovery Project scheme and the Centre of Excellence for Climate System Science. R. Hood was supported by a CSIRO Frohlich fellowship. R. J. Matear is supported by the CSIRO Wealth from Oceans National Flagship. M. J. McPhaden is supported by NOAA. This is NOAA/PMEL contribution number 4113 and UMCES contribution number 4963.

Edited by: S. W. A. Naqvi 


\section{References}

Blain, S., Queguiner, B., Armand, L., Belviso, S., Bombled, B., Bopp, L., Bowie, A., Brunet, C., Brussaard, C., Carlotti, F., Christaki, U., Corbiere, A., Durand, I., Ebersbach, F., Fuda, J.L., Garcia, N., Gerringa, L., Griffiths, B., Guigue, C., Guillerm, C., Jacquet, S., Jeandel, C., Laan, P., Lefevre, D., Lomonaco, C., Malits, A., Mosseri, J., Obernosterer, I., Park, Y.-H., Picheral, M., Pondaven, P., Remeny, T., Sandroni, V., Sarthou, G., Savoye, N., Scouarnec, L., Souhaut, M., Thuiller, D., Timmermans, K., Trull, T., Uitz, J., van-Beek, P., Veldhuis, M., Vincent, D., Viollier, E., Vong, L., and Wagener, T.: Effect of natural iron fertilisation on carbon sequestration in the Southern Ocean, Nature, 446, 10701074, 2007.

Bonjean, F. and Lagerloef, G. S. E.: Diagnostic model and analysis of the surface currents in the tropical Pacific Ocean, J. Phys. Oceanogr., 32, 2938-2954, 2002.

Chatterjee, A., Shankar, D., McCreary, J. P., and Vinayachandran, P. N.: Yanai waves in the western equatorial Indian Ocean, J. Geophys. Res., 118, 1556-1570, 2013.

Chen, D., Rothstein, L. M., and Busalacchi, A. J.: A hybrid vertical mixing scheme and its application to tropical ocean models, J. Phys. Oceanogr., 24, 2156-2179, 1994.

David, D. T., Kumar, S. P., Byju, P., Sarma, M. S. S., Suryanarayana, A., and Murty, V. S. N.: Observational evidence of lowerfrequency Yanai waves in the central equatorial Indian Ocean, J. Geophys. Res., 116, C06009, doi:10.1029/2010JC006603, 2011.

Dee, D.P. and Uppala, S.: Variational bias correction of satellite radiance data in the ERA-Interim reanalysis, Quarterly J. Roy. Meteorol. Soc., 135, 1830-1841, 2009.

Griffies, S. M.: Elements of MOM4p1, GFDL Ocean Group Technical Report 6, in: NOAA/Geophysical Fluid Dynamics Laboratory, 2009.

Griffies, S. M. and Hallberg, R. W.: Biharmonic friction with a Smagorinsky-like viscosity for use in large-scale eddypermitting ocean models, Month. Weather Rev., 128, 2935-2946, 2000.

Han, W., McCreary, J. P., Anderson, D. L. T., and Mariano, A. J.: Dynamics of the eastern surface jets in the equatorial Indian Ocean, J. Phys. Oceanogr., 29, 2191-2209, 1999.

Hendon, H. H. and Salby, M. L.: The life cycle of the Madden-Julian Oscillation, J. Atmos. Sc., 51, 2225-2237, 1994.

Hood, R. R., Wiggert, J. D., and Naqvi, S. W. A.: Indian Ocean Research: Opportunities and challenges, in: Indian Ocean Biogeochemical Processes and Ecological Variability, in: AGU Monograph Series, American Geophysical Union, Washington DC, 2009.

Horii, T., Ueki, I., Ando, K., and Mizuno, K.: Eastern Indian Ocean warming associated with the negative Indian Ocean dipole: A case study of the 2010 event, J. Geophys. Res., 118, 536-549, 2013.

Ihara, C., Kushnir, Y., and Cane, M. A.: Warming trend of the Indian Ocean SST and Indian Ocean Dipole from 1880 to 2004, J. Clim., 21, 2035-2046, 2008.

International CLIVAR Project Office: Understanding the role of the Indian Ocean in the climate system - Implementation plan for sustained observations, in: CLIVAR Publication Series, 100, Southampton, UK, 2006.

Joseph, S., Wallcraft, A. J., Jensen, T. G., Ravichandran, M., Shenoi, S. S. C., and Nayak, S.: Weakening of spring Wyrtki jets in the
Indian Ocean during 2006-2011, J. Geophys. Res., 117, C04012, doi:10.1029/2011JC007581, 2012.

Kidston, M., Matear, R., and Baird, M. E.: Parameter optimisation of a marine ecosystem model at two contrasting stations in the Sub-Antarctic Zone, Deep-Sea Res. Pt. II, 58, 2301-2315, 2011.

Legeckis, R., Brown, C. B., Bonjean, F., and Johnson, E. S.: The influence of tropical instability waves and phytoplankton blooms in the wake of the Marquesas Islands during 1998 and on the currents observed during the drift of the Kon-Tiki in 1947, Geophys. Res. Lett., 31, 1-4, 2004.

Madden, R. A. and Julian, P. R.: Detection of a 40-50 day oscillation in the zonal wind field in the tropical Pacific, J. Atmos. Sci., 28, 702-708, 1971.

McPhaden, M. J. and Foltz, G. R.: Intraseasonal variations in the surface layer heat balance of the central equatorial Indian Ocean: The importance of zonal advection and vertical mixing, Geophys Res. Lett., 40, 1-5, 2013.

McPhaden, M. J., Meyers, G., Ando, K., Masumoto, Y., Murty, V. S. N., Ravichandran, M., Syamsudin, F., Vialard, J., Yu, L., and Yu, W.: RAMA: The Research Moored Array for AfricanAsian-Australian Monsoon Analysis and Prediction, Bull. Am. Meteorol. Soc., 90, 459-480, 2009a.

McPhaden, M. J., Meyers, G., Ando, K., Masumoto, Y., Murty, V. S. N., Ravichandran, M., Syamsudin, F., Vialard, J., Yu, L., and Yu, W.: Supplement to RAMA: The Research Moored Array for African - Asian - Australian Monsoon Analysis and Prediction, Bull. Am. Meteorol. Soc., 90, ES5-ES8, 2009b.

Miyama, T., McCreary, J. P., Sengupta, D., and Senan, R.: Dynamics of Biweekly Oscillations in the Equatorial Indian Ocean, J. Phys. Oceanogr., 36, 827-846, 2006.

Nagura, M. and McPhaden, M. J.: Wyrtki jet dynamics: Seasonal variability, J. Geophys. Res., 115, C07009, doi:10.1029/2009JC005922, 2010a.

Nagura, M. and McPhaden, M. J.: Dynamics of zonal current variations associated with the Indian Ocean dipole, J. Geophys. Res. 115, C11026, doi:10.1029/2010JC006423, 2010 b.

Oke, P. R., Griffin, D., Schiller, A., Matear, R. J., Fiedler, R., Mansbridge, J., Cahill, M., Chamberlain, M. A., and Ridgway, K. R. Validation of a near-global eddy-resolving ocean model, Geosci Model Develop., 6, 1-25, 2013.

Prasanna Kumar, S., Divya David, T., Byju, P., Narvekar, J., Yoneyama, K., Nakatani, N., Ishida, A., Horii, T., Masumoto, Y., and Mizuno, K.: Bio-physical coupling and ocean dynamics in the central equatorial Indian Ocean during 2006 Indian Ocean Dipole, Geophys. Res. Lett., 39, L14601, doi:10.1029/2012GL052609, 2012.

Rao, R. R. and Sivakumar, R.: Seasonal variability of near-surface thermal structure and heat budget of the mixed layer of the tropical Indian Ocean from a new global ocean temperature climatology, J. Geophys. Res., 105, 995-1015, 2000.

Rao, R. R. and Sivakumar, R.: Seasonal variability of sea surface salinity and salt budget of the mixed layer of the north Indian Ocean, J. Geophys. Res., 108, 3009, doi:10.1029/2001JC000907, 2003.

Resplandy, L., Vialard, J., Levy, M., Aumont, O., and Dandonneau, Y.: Seasonal and intraseasonal biogeochemical variability in the thermocline ridge of the southern tropical Indian Ocean, J. Geophys. Res., 114, C07024, doi:10.1029/2008JC005246 2009. 
Ridgway, K. R., Dunn, J. R., and Wilkin, J. L.: Ocean interpolation by four-dimensional weighted least squares - Application to the waters around Australasia, J. Ocean. Atmos. Technol., 19, 13571375, 2002.

Risien, C. M. and Chelton, D. B.: A Global Climatology of Surface Wind and Wind Stress Fields from Eight Years of QuikSCAT Scatterometer Data, J. Phys. Oceanogr., 38, 2379-2413, 2008.

Roemmich, D. and Gilson, J.: The 2004-2008 mean and annual cycle of temperature, salinity, and steric height in the global ocean from the Argo program, Prog. Oceanogr., doi:10.1016/j.pocean.2009.03.004., 81-100, 2009.

Saji, N. H., Goswami, B. N., Vinayachandran, P. N., and Yamagata, T.: A dipole in the tropical Indian Ocean, Nature, 401, 360-363, 1999.

Schott, F. and McCreary, J. P.: The monsoon circulation of the Indian Ocean, Prog. Oceanogr., 51, 1-123, 2001.

Schott, F. A., Xie, S.-P., and McCreary Jr., J. P.: Indian Ocean circulation and climate variability, Rev. Geophys., 47, RG1002, doi:10.1029/2007RG000245, 2009.

Sengupta, D., Senan, R., Murty, V. S. N., and Fernando, V.: A biweekly mode in the equatorial Indian Ocean, J. Geophys. Res., 109, C10003, doi:10.1029/2004JC002329, 2004.
Shinoda, T.: Observation of first and second baroclinic mode Yanai waves in the ocean, Quarterly J. Roy. Meteorol. Soc., 138, 1018$1024,2012$.

Vinayachandran, P. N. and Nanjundiah, R. S.: Indian Ocean sea surface salinity variations in a coupled model, Clim. Dynam., 33, 245-263, 2009.

Waliser, D. E., Murtugudde, R., Strutton, P., and Li, J.-L.: Subseasonal organization of ocean chlorophyll: Prospects for prediction based on the Madden-Julian Oscillation, Geophys. Res. Lett., 32, L23602, doi:10.1029/2005GL024300, 2005.

Wiggert, J. D., Murtugudde, R. G., and Christian, J. R.: Annual ecosystem variability in the tropical Indian Ocean : Results of a coupled bio-physical ocean general circulation model, Deep-Sea Res. II, 53, 644-676, 2006.

Wyrtki, K.: An equatorial jet in the Indian Ocean, Science, 181, 262-264, 1973a.

Wyrtki, K.: Physical oceanography of the Indian Ocean, in: The biology of the Indian Ocean, edited by: Zeitschel, B., SpringerVerlag, Berlin, 18-36, 1973 b.

Yanai, M. and Maruyama, T.: Stratospheric wave disturbances propagating over the equatorial pacific, J. Meteorol. Soc. Jap., 44, 291-294, 1966. 